\title{
Baseline characteristics of outpatients with heart failure according to phenotype: preliminary analysis from SMYRNA- HF registry
}

\author{
Bihter Şentürk $^{1} \odot$, Ahmet Çelik ${ }^{2} \odot$, Lütfü Bekar ${ }^{3} \odot$, Umut Uyan ${ }^{4}$, Selcen Yakar Tülüce ${ }^{5} \odot$, Hakan \\ Güneş $^{6} \odot$, Murat Kerkütlüoğlu ${ }^{6} \odot$, Ali Çoner ${ }^{7} \odot$, Barış Kılıçaslan ${ }^{8} \odot$, Nurullah Çetinn ${ }^{9} \odot$, Ayşe Çolak ${ }^{1} \odot$, \\ Burak Açar $^{10} \odot$, İlker Gül ${ }^{11} \odot$, Cihan Altın ${ }^{12} \odot$, Yalçın Özkurt ${ }^{11} \odot$, Makbule Kutlu Karadağ ${ }^{11} \odot$, Ezgi \\ Kalaycıoğlu $^{13} \odot$, Mesut Özkahya ${ }^{1} \odot$, Tuba Ekin ${ }^{1}$, Nuryıl Yılmaz ${ }^{14} \odot$, Mehmet Birhan Yılmaz ${ }^{1} \odot$
}

\author{
${ }^{1}$ Department of Cardiology, Dokuz Eylül University, Faculty of Medicine, İzmir, Turkey \\ ${ }^{2}$ Department of Cardiology, Mersin University, Faculty of Medicine, Mersin, Turkey \\ ${ }^{3}$ Department of Cardiology, Hitit University, Faculty of Medicine, Çorum, Turkey \\ ${ }^{4}$ Department of Cardiology, Ödemiş State Hospital, Izmir, Turkey \\ ${ }^{5}$ Department of Cardiology, Izmir Katip Celebi University, Atatürk Training and Research Hospital, Izmir, Turkey \\ ${ }^{6}$ Department of Cardiology, Kahramanmaraş Sütçü Imam University, Faculty of Medicine, Kahramanmaraş, Turkey \\ ${ }^{7}$ Department of Cardiology, Başkent University, Alanya Hospital, Antalya, Turkey \\ ${ }^{8}$ Department of Cardiology, University of Health Sciences, İmir Tepecik Health Research Center, Izmir, Turkey \\ ${ }^{9}$ Department of Cardiology, Manisa Celal Bayar University, Faculty of Medicine, Manisa, Turkey \\ ${ }^{10}$ Department of Cardiology, Kocaeli University, Faculty of Medicine, Kocaeli, Turkey \\ ${ }^{11}$ Department of Cardiology, Torball State Hospital, Izmir, Turkey \\ ${ }^{12}$ Department of Cardiology, Başkent University, Zübeyde Hanım Hospital, İzmir, Turkey \\ ${ }^{13}$ Department of Cardiology, University of Health Sciences, Trabzon Ahi Evren Health Research Center for Thoracic and Cardiovascular \\ Surgery, Trabzon, Turkey \\ ${ }^{14}$ Department of Psychiatry, University of Health Sciences, İzmir Tepecik Health Research Center, İzmir, Turkey
}

\section{ABSTRACT}

Objectives: SMYRNA-HF study is a prospective multicenter registry study to determine the profiles of patients with heart failure (HF) in Turkey. This study aimed to present the baseline characteristics of preliminary cohort by comparing them according to different HF phenotypes.

Methods: The first SMYRNA-HF cohort included outpatients with HF from 9 centers. Patients were classified into three HF phenotypes as HF with reduced ejection fraction (HFrEF), mildly reduced EF (HFmrEF), and preserved EF (HFpEF) as recommended by guidelines.

Results: Overall, 298 patients were included in this preliminary analysis that $57 \%$ of the patients were classified as having HFrEF, 33.3\% as having HFpEF, and 9.7\% as having HFmrEF. Female gender was more common in HFpEF $(p=0.003)$. Age, frequency of diabetes mellitus, use of angiotensin-converting enzyme inhibitors/angiotensin receptor blocker, use of beta-blocker, use of daily loop diuretic, heart rate, blood urea nitrogen levels, lipid profiles, hemoglobin, white blood cell, platelet levels were similar among three HF phenotypes. Body mass index (BMI) $(p<0.001)$, frequency of hypertension (HT) $(p<0.001)$, and atrial fibrillation (AF) $(p=0.015)$ were higher in HFpEF. Ischemic etiology $(p<0.001)$ was less frequent in HFpEF. Use of mineralocorticoid receptor antagonist was higher in $\operatorname{HFrEF}(p<0.001)$.

Conclusions: Our study presented the baseline characteristics of outpatients with HF in Turkey. There were

How to cite this article: Şentürk B, Çelik A, Bekar L, Uyan U, Yakar Tülüce S, Güneş H, et al. Baseline characteristics of outpatients with heart failure according to phenotype: preliminary analysis from SMYRNA-HF registry. Eur Res J 2022;8(2):266-274. DOI: 10.18621/eurj.1049360

Address for correspondence: Bihter Şentürk, MD., Assistant Professor, Dokuz Eylul University, Faculty of Medicine, Department of Cardiology, İzmir, Turkey.E-mail:drbihter@hotmail.com,Tel:+902324124111 
significant differences among HF phenotypes in terms of gender, BMI, frequency of HT, AF, and ischemic etiology. Treatment implementations seem to follow the guidelines. Although the rates are low, new treatment approaches recommended in the most recent guidelines seem to enter clinical practice.

Keywords: Heart failure, registries, Turkey, phenotypes, outpatients, baseline characteristics

$\mathrm{H}$ eart failure (HF) is a fatal disease that occurs as a result of deterioration of cardiac functions. It is estimated that there are approximately 40 million patients with $\mathrm{HF}$ in the world. The number of patients with HF is anticipated to increase in the coming years [1]. Many notable improvements have been observed in the treatment of HF, and there has been a remarkable increase in the life expectancy of patients with HF $[2,3]$. Nevertheless, these patients still are at risk of death or acute decompensation requiring recurrent hospitalization.

Large-scale multicenter HF cohort registry studies have been conducted in many countries [4-13]. These studies provide important data regarding the basic profiles of patients, the distribution of HF phenotypes, risk factors, treatment, mortality, and morbidity characteristics of patients with HF from different countries. The "SELFIE-TR study" that includes the basal characteristics, treatments [14], and mortality data [15] of patients with different HF phenotypes has been recently published in Turkey.

More registry studies are required to understand better the profile of the patients with HF in our country. In this multicenter HF registry study called SMYRNA-HF, it was aimed to determine the profile of outpatients with HF in our country, to define the baseline characteristics of the patients, to examine whether these features differ between different HF phenotypes, and to evaluate the treatment of the patients.

\section{METHODS}

The SMYRNA-HF study is an ongoing prospective national registry study including outpatients with $\mathrm{HF}$ with a plan to recruit patients from centers in Turkey under the leading role of Izmir. In this registry study, long-term follow-up of the patients is aimed. The current study, which provides the data from the preliminary cohort of the SMYRNA-HF registry, recruited patients from 9 centers between October 2019 and January 2021. Patients with acute decompensated $\mathrm{HF}$ and hospitalized with acute decompensation within the last month were not considered.

Demographic and clinical characteristics of the patients, laboratory, electrocardiographic and echocardiographic findings, and medications at the time of enrolment were recorded. The diagnosis and phenotype categorization of patients with HF were made according to the current guidelines. The patients were classified into three HF phenotype groups; HF with reduced ejection fraction (HFrEF) if they had left ventricular ejection fraction (LVEF) $\leq 40 \%$, HF with mildly reduced ejection fraction (HFmrEF) if they had LVEF between $41 \%$ and $49 \%$; and HF with preserved ejection fraction (HFpEF) if they had LVEF $\geq 50 \%$ $[16,17]$. The New York Heart Association (NYHA) class was used to determine the functional capacities of patients.

Ethical approval for this study was provided by the Non-Invasive Research Ethics Committee of Dokuz Eylül University (date: 16.09.2019, approval No: 2019/23-39), the coordinating center, and each center approved participation in the study in accordance with established legislation.

\section{Statistical Analysis}

The Kolmogorov-Smirnov test was used to evaluate whether the data showed a normal distribution. Since all continuous variables showed a non-normal distribution, non-parametric analysis methods were used. The continuous variables were expressed as median (quartile 1-3), and the categorical variables were presented as numbers (\%). Differences in continuous variables between the three groups according to $\mathrm{HF}$ phenotype were analyzed with the Kruskal Wallis-H test. Differences between categorical variables were analyzed with the chi-square test. The significance level for all tests was determined as $p<0.05$. Statistical analysis was performed using the IBM SPSS Statistics for Windows (Version 25.0. Armonk, NY: IBM Corp.). 


\section{RESULTS}

A total of 298 patients with HF were included in this analysis. $57 \%$ of the patients were classified as having HFrEF, $33.3 \%$ as having $\mathrm{HFpEF}$, and $9.7 \%$ as having HFmrEF (Fig. 1). The median age of the patients was 67 (59-76) years, and 37\% of them were female. Previous acute coronary syndrome (ACS) was present in $54.7 \%$ of the patients. In addition, $30.9 \%$ of the patients had hypertension, and $28.2 \%$ had diabetes mellitus (DM). In the whole cohort, the median LVEF was $40 \%$ (30\%-52\%).Beta-blocker use was reported in $85.6 \%$, angiotensin-converting enzyme inhibitors (ACEI)/angiotensin receptor blocker (ARB) use was reported in $63.4 \%$, mineralocorticoid receptor antagonist (MRA) use was reported in $40.9 \%$, and daily loop diuretic use was reported in $79.2 \%$. In the whole cohort, the frequency of use of angiotensin receptor neprilysin inhibitors (ARNI) and sodium-glucose cotransporter-2 (SGLT2) inhibitors was $4.4 \%$ and $1.3 \%$, respectively. The frequency of implantable cardioverter defibrillator (ICD) and cardiac resynchronization therapy with defibrillator (CRT-D) was $10.4 \%$ and $2.3 \%$, respectively. The rhythm was atrial fibrillation in $24.2 \%$ of the patients. The baseline characteristics of patients, including demographic, clinical features, electrocardiographic and echocardiographic findings, laboratory parameters, and medications are

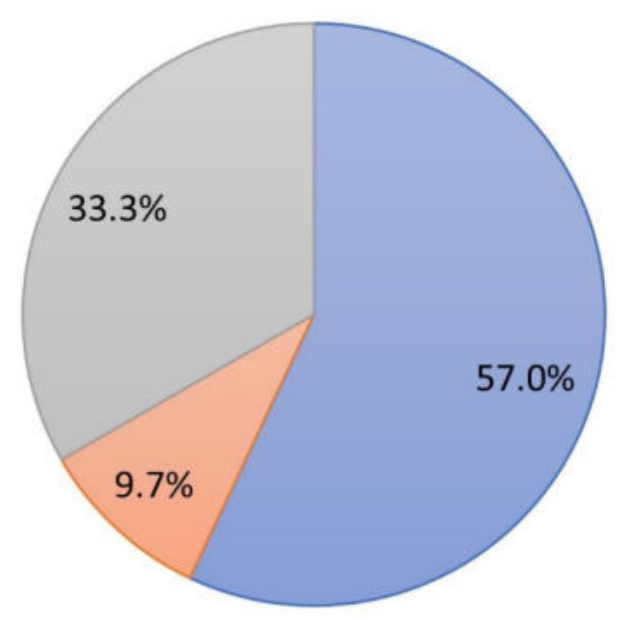

$\square \operatorname{HFrEF}(\%) \quad \square \operatorname{HFmrEF}(\%) \quad \square \operatorname{HFpEF}(\%)$

Fig. 1. Ratio of patients according to heart failure phenotypes. HFrEF = heart failure with reduced ejection fraction, HFmrEF $=$ heart failure with mildly reduced ejection fraction, $\mathrm{HFpEF}=$ heart failure with preserved ejection fraction. presented in Table 1.

Median LVEF was $31.5 \%$ in the patients with HFrEF, $45 \%$ in HFmrEF, and $55 \%$ in HFpEF $(p<$ 0.001 ). Age, frequency of DM, use of ACEI/ARB, use of beta-blocker, use of daily loop diuretic, heart rate, blood urea nitrogen levels, lipid profiles, hemoglobin, white blood cell, platelet levels were similar among three HF phenotypes (Table 2). Female gender was more common in the patients with $\operatorname{HFpEF}(p=0.003)$. The median body mass index (BMI) value $(p<0.001)$ and the frequency of hypertension, atrial fibrillation was higher ( $p<0.001$ and $p=0.015$, respectively), and the frequency of previous ACS was lower in the patients with HFpEF $(p<0.001)$. The median systolic blood pressure (SBP), diastolic blood pressure (DBP), and sodium level were lower in patients with HFrEF ( $p<0.001, p<0.001, p=0.002$, respectively). The median creatinine level and the frequency of use of MRA were higher in patients with $\operatorname{HFrEF}(p=0.003$, $p<0.001$, respectively). In addition, there were no significant differences among the groups with regard to frequency of poor NYHA functional class (NYHA class III-IV) ( $p=0.210)$ and echocardiographic parameters, including left atrium diameter, right ventricle diameter, and systolic pulmonary artery pressure (SPAP) ( $p=0.272, p=0.094, p=0.309$, respectively). Left ventricle end-diastolic diameter (LVEDD), endsystolic diameter (LVESD) were higher $(p<0.001, p$ $<0.001$ ), and tricuspid annular plane systolic excursion (TAPSE) was lower in patients with $\operatorname{HFrEF}(p=$ $0.024)$. The comparison results of patients' characteristics according to HF phenotypes are presented in Table 2.

\section{DISCUSSION}

The SMYRNA-HF study provides a real-life dataset of chronic HF outpatients with different HF phenotypes in reference to the European Society of Cardiology (ESC) guidelines published in 2021 [17]. SMYRNA-HF registry study aimed to reflect outpatients with HF in our country. The characteristics of the patients for each HF phenotype were determined and whether patients were on guideline-directed medical therapy or not considered thoroughly in this analysis. Of note, these patients have been on follow-up for outcomes. This registry overall purposes of determin- 
Table 1. Baseline characteristics of the whole cohort $(n=298)$

\section{Median (Quartiles 1-3)}

\begin{tabular}{|c|c|}
\hline Age (years) & $67(59-76)$ \\
\hline Female gender, n (\%) & $110(37.0)$ \\
\hline Body mass index $\left(\mathrm{kg} / \mathrm{m}^{2}\right)$ & $27.26(24.24-31.33)$ \\
\hline \multicolumn{2}{|l|}{ NYHA functional classification, $n(\%)$} \\
\hline Class I/II & $218(73.2)$ \\
\hline Class III/IV & $80(26.8)$ \\
\hline Systolic blood pressure (mmHg) & $120(110-136.5)$ \\
\hline Diastolic blood pressure (mmHg) & $70(69.5-80)$ \\
\hline Previous acute coronary syndrome, $n(\%)$ & $163(54.7)$ \\
\hline Diabetes mellitus, $\mathbf{n}(\%)$ & $84(28.2)$ \\
\hline Hypertension, n (\%) & $92(30.9)$ \\
\hline Atrial fibrillation, n (\%) & $72(24.2)$ \\
\hline Heart rate (beats/min) & $75(66-83.5)$ \\
\hline ICD, n (\%) & $31(10.4)$ \\
\hline CRT-D, n (\%) & $7(2.3)$ \\
\hline \multicolumn{2}{|l|}{ Echocardiography characteristics } \\
\hline LV end-diastolic diameter (mm) & $53(48-58)$ \\
\hline LV end-systolic diameter (mm) & $39.5(34-46)$ \\
\hline LVEF $(\%)$ & $40(30-52)$ \\
\hline SPAP (mmHg) & $38(34.5-45)$ \\
\hline TAPSE $(\mathrm{mm})$ & $16(14-18)$ \\
\hline Left atrium $(\mathrm{mm})$ & $44(41-48)$ \\
\hline Right ventricle (mm) & $37(32-40.3)$ \\
\hline \multicolumn{2}{|l|}{ Medication, n (\%) } \\
\hline Use of ACEI/ARB & $189(63.4)$ \\
\hline Use of betablocker & $255(85.6)$ \\
\hline Use of MRA & $122(40.9)$ \\
\hline Use of daily loop diuretic & $236(79.2)$ \\
\hline Use of SGLT2 inhibitor, n (\%) & $4(1.3)$ \\
\hline Use of ARNI, n (\%) & $13(4.4)$ \\
\hline \multicolumn{2}{|l|}{ Laboratory findings } \\
\hline Glucose (mg/dL) & $110(95-145)$ \\
\hline Blood urea nitrogen (mg/dL) & $18.5(15-27.8)$ \\
\hline Creatinine $(\mathrm{mg} / \mathrm{dL})$ & $1.0(0.8-1.3)$ \\
\hline Sodium $(\mathrm{mEq} / \mathrm{L})$ & $139(136-141)$ \\
\hline Potassium (mEq/L) & $4.4(4.1-4.8)$ \\
\hline Hemoglobin (g/dL) & $13.0(11.4-14.2)$ \\
\hline Platelet $\left(\times 10^{9} / \mathrm{L}\right)$ & $245.5(201.0-311.8)$ \\
\hline White blood cell $\left(\times 10^{9} / \mathrm{L}\right)$ & $8.0(6.7-10.0)$ \\
\hline Low-density lipoprotein (mg/dL) & $100.5(75.8-128.0)$ \\
\hline High-density lipoprotein(mg/dL) & $43.0(36.0-54.0)$ \\
\hline Triglyceride (mg/dL) & $115.0(90.8-170.0)$ \\
\hline Total cholesterol (mg/dL) & $172.0(141.8-200.0)$ \\
\hline
\end{tabular}

NYHA $=$ New York Heart Association, ICD $=$ implantable cardioverter defibrillator, CRT-D $=$ cardiac resynchronization therapy-defibrillator, $\mathrm{LV}=$ left ventricle, $\mathrm{LVEF}=$ left ventricular ejection fraction, SPAP $=$ systolic pulmonary artery pressure, TAPSE $=$ tricuspid annular plane systolic excursion, ACEI $=$ angiotensin- converting enzyme inhibitor, $\mathrm{ARB}=$ angiotensin receptor blocker, MRA $=$ mineralocorticoid receptor antagonist, SGLT2 $=$ sodium-glucose cotransporter-2, ARNI $=$ angiotensin receptor neprilysin inhibitor 
Table 2. Comparison of baseline characteristics according to heart failure phenotypes $(n=298)$

\begin{tabular}{|c|c|c|c|c|}
\hline & $\begin{array}{c}\text { HFrEF } \\
(n=170)\end{array}$ & $\begin{array}{c}\text { HFmrEF } \\
(\mathrm{n}=29)\end{array}$ & $\begin{array}{l}\text { HFpEF } \\
(\mathrm{n}=99)\end{array}$ & $p$ value \\
\hline Age (years) & $66(58-75)$ & $67(57-75)$ & $69(62-77)$ & 0.289 \\
\hline Female gender, n (\%) & $51(30.2)$ & $9(31.0)$ & $50(50.5)$ & $0.003 *$ \\
\hline Body mass index $\left(\mathrm{kg} / \mathrm{m}^{2}\right)$ & $25.9(23.4-29.4)$ & $28.1(25.1-32.1)$ & $29.4(26.3-33.5)$ & $<0.001 *$ \\
\hline $\begin{array}{l}\text { NYHA functional classification - Class } \\
\text { III/IV, } \mathrm{n}(\%)\end{array}$ & $46(27.1)$ & $4(13.8)$ & $30(30.3)$ & 0.210 \\
\hline Systolic blood pressure (mmHg) & $120(110-130)$ & $130(120-140)$ & $130(115-140)$ & $<0.001 *$ \\
\hline Diastolic blood pressure (mmHg) & $70(62-75)$ & $80(70-90)$ & $70(70-80)$ & $<0.001 *$ \\
\hline Previous acute coronary syndrome, $\mathbf{n}(\%)$ & $110(64.7)$ & $21(72.4)$ & $32(32.3)$ & $<0.001 *$ \\
\hline Diabetes mellitus, $\mathbf{n}(\%)$ & $42(24.7)$ & $11(37.9)$ & $31(31.3)$ & 0.240 \\
\hline Hypertension, n (\%) & $30(17.6)$ & $13(44.8)$ & $49(49.5)$ & $<0.001 *$ \\
\hline Atrial fibrillation, $\mathrm{n}(\%)$ & $35(22.7)$ & $3(11.1)$ & $34(35.4)$ & $0.015^{*}$ \\
\hline Heart rate (beats/min) & $75.5(67-85)$ & $70(61-80)$ & $76(67-84)$ & 0.177 \\
\hline \multicolumn{5}{|l|}{ Echocardiography characteristics } \\
\hline LV end-diastolic diameter $(\mathrm{mm})$ & $56(52-61.5)$ & $52(48-56)$ & $48(43-51)$ & $<0.001 *$ \\
\hline LV end-systolic diameter (mm) & $44(40-50)$ & $38.5(37-41)$ & $33(30-36)$ & $<0.001 *$ \\
\hline LVEF (\%) & $31.5(25-40)$ & $45(45-46.5)$ & $55(51-60)$ & $<0.001 *$ \\
\hline SPAP (mmHg) & $40(34-46)$ & $35(30-40)$ & $38(35-45)$ & 0.309 \\
\hline TAPSE (mm) & $16(13-18)$ & $16.5(16-19)$ & $17(15-19)$ & $0.024^{*}$ \\
\hline Left atrium $(\mathrm{mm})$ & $44(41-48)$ & $43(38-46)$ & $45(42-48)$ & 0.272 \\
\hline Right ventricle (mm) & $38(33-40)$ & $32(28-39)$ & $37(31-41)$ & 0.094 \\
\hline \multicolumn{5}{|l|}{ Medication, n (\%) } \\
\hline Use of ACEI/ARB & $108(63.5)$ & $20(69.0)$ & $61(61.6)$ & 0.769 \\
\hline Use of betablocker & $151(88.8)$ & $26(89.7)$ & $78(78.8)$ & 0.063 \\
\hline Use of daily loop diuretic & $137(80.3)$ & $19(65.5)$ & $80(80.8)$ & 0.161 \\
\hline Use of MRA & $90(52.9)$ & $12(41.4)$ & $20(20.2)$ & $<0.001 *$ \\
\hline \multicolumn{5}{|l|}{ Laboratory findings } \\
\hline Glucose (mg/dL) & $110.5(96-148)$ & $111(85.5-138)$ & $108(94.5-131)$ & 0.491 \\
\hline Blood urea nitrogen (mg/dL) & $20(16-30)$ & $17.5(16.5-20.5)$ & $17(14-24)$ & 0.059 \\
\hline Creatinine (mg/dL) & $1.1(0.9-1.4)$ & $1.0(0.8-1.3)$ & $1.0(0.8-1.2)$ & $0.003^{*}$ \\
\hline Sodium $(\mathrm{mEq} / \mathrm{L})$ & $138(136-140)$ & $140(138-142)$ & $140(137-141)$ & $0.002 *$ \\
\hline Potassium $(\mathrm{mEq} / \mathrm{L})$ & $4.4(4.08-4.8)$ & $4.4(4.2-4.6)$ & $4.4(4.1-4.8)$ & 0.986 \\
\hline Hemoglobin (g/dL) & $13(11.5-14.3)$ & $12.7(11-13.8)$ & $12.9(11.4-14.1)$ & 0.878 \\
\hline Platelet $\left(\times 10^{9} / \mathrm{L}\right)$ & $242(193-307)$ & $234(207-299)$ & $255(209-319.5)$ & 0.253 \\
\hline White blood cell $\left(\times 10^{9} / \mathrm{L}\right)$ & $7.9(6.8-9.5)$ & $9.4(7-11.4)$ & $8.1(6.4-10)$ & 0.210 \\
\hline Low-density lipoprotein (mg/dL) & $99(77.5-124.5)$ & $90(63-143)$ & $104(77-128)$ & 0.801 \\
\hline High-density lipoprotein(mg/dL) & $44(36-53)$ & $41(35-56)$ & $43.5(37-54)$ & 0.905 \\
\hline Triglyceride (mg/dL) & $113(83-155)$ & $139(105-195)$ & $114.5(91-161)$ & 0.541 \\
\hline Total cholesterol (mg/dL) & $173(142-210)$ & $161(144-200)$ & $170.5(141-194)$ & 0.804 \\
\hline
\end{tabular}

Data are presented as median (Quartiles 1-3) unless otherwise stated. ${ }^{*} p<0.05$. HFrEF $=$ heart failure with reduced ejection fraction, $\mathrm{HFmrEF}=$ heart failure with mildly reduced ejection fraction, $\mathrm{HFpEF}=$ heart failure with preserved ejection fraction, NYHA $=$ New York Heart Association, LV = left ventricle, $\mathrm{LVEF}=$ left ventricular ejection fraction, SPAP $=$ systolic pulmonary artery pressure, TAPSE $=$ tricuspid annular plane systolic excursion, $\mathrm{ACEI}=$ angiotensin-converting enzyme inhibitor, $\mathrm{ARB}=$ angiotensin receptor blocker, $\mathrm{MRA}=$ mineralocorticoid receptor antagonist 
ing the barriers to the management of HF and identifying predictors of mortality and recurrent hospitalization. Baseline characteristics of this preliminary cohort were presented herein.

In the ESC registry study, including outpatients with HF, $60 \%$ of the patients had HFrEF, $24 \%$ had HFmrEF, and $16 \%$ had HFpEF [18]. Similar to the ESC registry study, $57 \%$ of the patients were found to have HFrEF in our study. While $42.9 \%$ of patients with HF had ischemic etiology in the ESC registry study, this rate was $54.7 \%$ in our study. Similar to our study, ischemic etiology was found in more than half $(52.6 \%)$ of the patients in the chronic HF group of the SELFIE-TR study [14]. The higher rate of ischemic etiology in HF (i.e., previous ACS) in our country compared to Europe indicates that we need to move faster in diagnosis and hyperacute treatment, especially in ST-segment elevation myocardial infarction, and improve the quality of primary percutaneous coronary interventions [19]. In our study, the frequency of HFpEF was found to be $33.3 \%$. In the SELFIE-TR study, the frequency of HFpEF was only $7.3 \%$ in the whole cohort [14]. In general, patients with HFpEF have multiple comorbidities; the diagnosis with $\mathrm{HF}$ and follow-up by a cardiologist is delayed due to overlapping symptoms. Compared to the SELFIE-TR study, the higher frequency of HFpEF in our study can be interpreted as an increased awareness of HFpEF in both physicians and patients.

In general, patients with HFpEF are older and more frequently women than patients with HFrEF and HFmrEF. Patients with HFpEF have more frequent atrial fibrillation compared to patients with HFrEF and HfmrEF [20]. In the HAPPY study investigating the prevalence of HF in Turkey, the male gender ratio was higher in the subgroup of $\mathrm{HF}$ with $\mathrm{LVEF}<50 \%$, and the female gender ratio was higher in the subgroup of HF with LVEF $\geq 50 \%$ [21]. In our study, half of the patients with HFpEF were women; although the median age was numerically higher in patients with HFpEF, it did not reach statistical significance.

HFmrEF is more akin to HFrEF than the HFpEF phenotype; patients with these two phenotypes (HFmrEF and HFrEF) have a higher male gender ratio, younger age, are more likely to have ischemic etiology, and are less likely to have atrial fibrillation compared to patients with HFpEF [22-24]. In the APOLLON study comparing the clinical features of patients with HFmrEF and HFpEF in Turkey, the mean ages of the two groups were similar; the female gender ratio was higher in patients with HFpEF, and the ratio of previous myocardial infarction was higher in those with HFmrEF [25]. Consistent with the literature, in our study, approximately $70 \%$ of patients with HFmrEF and HFrEF were male, their median age was similar, and the underlying ischemic etiology was higher in patients with HFmrEF and HFrEF than in those with HFpHF. While more than half of the patients with HFmrEF and HFrEF had previous ACS, this rate was $32.3 \%$ in those with HFpEF.

Obesity is one of the major causes of HFpEF [20, 26-28]. BMI assessment is important in patients with HF. In our study, the HF phenotype with the highest BMI was HFpEF. Hypertension is the most important cause of HFpEF [29]. In our study, nearly half of the patients with HFpEF were found to have hypertension. In our study, the proportions of patients with NYHA functional class III-IV were similar in patients with HFrEF and HFpEF (27.1\% vs. 30.3\%, respectively) along with similar age distribution. However, the NYHA functional class assessment is based on symptoms only. Non-cardiac comorbidities are more common in HFpEF, and it may be difficult to distinguish whether symptoms are primarily and solely caused by HF or by other non-cardiac diseases [30]. Therefore, the frequency of patients with poor NYHA functional class may have been found to be similar in patients with HFrEF and HFpEF.

In our study, SBP and DBP were found to be lower in patients with HFrEF. Similarly, in the ESC registry study, SBP was lower, and hypotension $(\mathrm{SBP} \leq 110$ $\mathrm{mmHg}$ ) was more frequent in patients with $\mathrm{HFrEF}$ [13]. These results may simply be associated with a high frequency of hypertension in patients with HFpEF.

Most of the deaths are caused by electrical disturbances, including ventricular arrhythmias in patients with HFrEF. ICD or CRT-D are recommended to reduce mortality in these patients when specific indications are provided [17]. In our study, all patients with ICD/CRT-D were in the HFrEF phenotype. The rate of ICD and CRT-D were $18.2 \%$ and $4.1 \%$, respectively in patients with HFrEF. In the ESC registry study, the same rates were $34.8 \%$ and $22.4 \%$, respectively [18]. Although it is difficult to make a comparison due to the small number of patients, the rate of patients with 
ICD/CRT-D was low in our cohort. In the CRT Survey-II study, 11,088 patients who are candidates for CRT were recruited from 288 centers, the median number of CRT implantations per year in Turkey was found to be significantly lower than in other European countries [31]. Management of HF especially device threapy is expensive [32]. The lower rate of device therapy in HF in our country may be due to cost-effectiveness problem. Conservative approach of patients and physicians may also be another reason. Nevertheless, it would be appropriate to improve the implementation of ICD and CRT-D in eligible patients.

The ACE-I/ARB/ARNI, beta-blocker, and MRA triad are the cornerstone of treatment for patients with HFrEF $[13,33,34]$. In these study, $63.5 \%$ of patients with HFrEF were on ACE-I or ARB and $88.8 \%$ of those on beta-blocker. In the ATA study, including patients with HFrEF from Turkey, renin-angiotensin system (RAS) inhibitors and beta-blocker usage were $78.2 \%$ and $90.2 \%$, respectively [35]. In our country, the rate of use of beta-blocker was satisfactory in patients with HFrEF, but the same cannot be said for RAS inhibitors. Replacement of ACE-I or ARB with ARNI is recommended in symptomatic patients with ambulatory HFrEF [17], but only $7.6 \%$ of patients with HFrEF were on ARNI in this cohort. The low usage rate of this drug can be explained by the lack of reimbursement in our country. SGLT2 inhibitors have been reported to reduce the risk of death in patients with HFrEF [36, 37]; thus, SGLT2 inhibitors were recommended for all patients with HFrEF in the recent ESC guideline [17]. In our study, only $2.3 \%$ of the patients with HFrEF were on SGLT2 inhibitors. This rate was quite low. However, SGLT2 inhibitors have recently entered the guidelines. We think that the use of SGLT2 inhibitors will increase significantly in the coming years.

There are no specific studies on medical therapy in patients with HFmrEF [17]. However, many patients with HFmrEF are also treated with ACE-I/ARBs because of ischemic heart disease, hypertension, or systolic dysfunction after ACS. A beta-blocker is used in many patients with HFmrEF because of atrial fibrillation or angina [17]. Of note, to date, only empagliflozin has been demonstrated to improve outcomes in patients with HFpEF [38]. Nevertheless, most of the patients with HFpEF have hypertension and atrial fibrillation; these patients are also on ACE-
I/ARBs and beta-blockers. In a large randomized controlled study involving 4822 patients with HFpEF, it was reported that $86 \%$ of the patients were on ACEI/ARBs, and $80 \%$ of them were on beta-blockers [39]. In our study, we think that the rate of use of ACEI/ARBs and beta-blockers was similar in all three HF phenotypes due to other compelling cardiovascular indications. MRAs are recommended for all patients with HFrEF to reduce mortality [40, 41], but MRAs do not have clear-cut indications for patients with HFpEF and HFmrEF. Consistent with these findings, the use of MRAs was found to be significantly higher in patients with HFrEF in our study. However, only $52.9 \%$ of the patients with HFrEF were on MRAs; this ratio was $55.4 \%$ in the ATA study [35]. In the light of these data, it should be aimed to increase the use of RAS inhibitors and MRAs in patients with HFrEF unless severe renal dysfunction, symptomatic hypotension and hyperkalemia. In the Hit-Point trial, the clinical benefits of enhanced HF education with a telephone follow-up program were demonstrated in patients with HFrEF [42]. Therefore, these patients should be monitored more closely to improve patient compliance and optimize medical therapy.

\section{Limitations}

First, our study has a small sample size. In addition, the patients were recruited only from cardiology clinics, and we did not consider patients with chronic HF examined by other physicians such as internists. Since echocardiography was administered during routine outpatient practice, it was limited to assessing cardiac functions and structure. Detailed echocardiography and hemodynamic assessment were not part of the evaluation of these patients in the majority of the cases. Due to the multicenter nature of our study, standardization could not be made for LVEF measurement. Some patients with LVEF values, especially close to the cutoff values, may have been misclassified due to the differences between the performing physicians.

\section{CONCLUSION}

Our study presented the baseline characteristics of patients with HF in our country. It was determined that there were significant differences in patients with dif- 
ferent HF phenotypes in terms of BMI, gender, frequency of having ischemic etiology, hypertension, and atrial fibrillation. Treatment approaches were generally in accordance with the guidelines. In addition, although the rates are low, new treatment approaches recommended in the most recent guidelines seem to enter clinical practice.

\section{Authors' Contribution}

Study Conception: BŞ, Ah.Çe., LB, UU, SYT, HG, MK, Al.Ço., BK, NÇ, Ay.Ço., BA, İG, CA, YÖ, MKK, EK, MÖ, TE, NY, MBY; Study Design: BŞ, Ah.Çe., LB, UU, SYT, HG, MK, Al.Ço., BK, NÇ, Ay.Ço., BA, İG, CA, YÖ, MKK, EK, MÖ, TE, NY, MBY; Supervision: BŞ, Ah.Çe., MBY; Funding: N/A; Materials: BŞ, Ah.Çe., LB, UU, SYT, HG, MK, Al.Ço., BK, NÇ, Ay.Ço., MÖ, TE, MBY; Data Collection and/or Processing BŞ, Ah.Çe., LB, UU, SYT, HG, MK, Al.Ço., BK, NÇ, Ay.Ço., MÖ, TE; Statistical Analysis and/or Data Interpretation: BŞ, MBY; Literature Review: BŞ, MBY; Manuscript Preparation: BŞ, MBY and Critical Review: BŞ, Ah.Çe., LB, UU, SYT, HG, MK, Al.Ço., BK, NÇ, Ay.Ço., BA, İG, CA, YÖ, MKK, EK, MÖ, TE, NY, MBY.

\section{Conflict of interest}

The authors disclosed no conflict of interest during the preparation or publication of this manuscript.

\section{Financing}

The authors disclosed that they did not receive any grant during conduction or writing of this study.

\section{REFERENCES}

1. Ziaeian B, Fonarow GC. Epidemiology and aetiology of heart failure. Nat Rev Cardiol 2016;13:368-78.

2. Parén P, Schaufelberger M, Björck L, Lappas G, Fu M, Rosengren A. Trends in prevalence from 1990 to 2007 of patients hospitalized with heart failure in Sweden. Eur J Heart Fail 2014; 16:737-42.

3. Schmidt M, Ulrichsen SP, Pedersen L, Bøtker HE, Sørensen HT. Thirty-year trends in heart failure hospitalization and mortality rates and the prognostic impact of co-morbidity: a Danish nationwide cohort study. Eur J Heart Fail 2016;18:490-9.

4. Tavazzi L, Senni M, Metra M, Gorini M, Cacciatore G, Chinaglia $\mathrm{A}$, et al. Multicenter prospective observational study on acute and chronic heart failure: one-year follow-up results of INHF (Italian Network on Heart Failure) outcome registry. Circ
Heart Fail 2013;6:473-81.

5. Ogah OS, Stewart S, Falase AO, Akinyemi JO, Adegbite GD, Alabi AA, et al. Short-term outcomes after hospital discharge in patients admitted with heart failure in Abeokuta, Nigeria: data from the Abeokuta Heart Failure Registry. Cardiovasc J Afr 2014;25:217-23.

6. Lee SE, Cho HJ, Lee HY, Yang HM, Choi JO, Jeon ES, et al. A multicentre cohort study of acute heart failure syndromes in Korea: rationale, design, and interim observations of the Korean Acute Heart Failure (KorAHF) registry. Eur J Heart Fail 2014;16:700-8.

7. Yancy CW, Lopatin M, Stevenson LW, De Marco T, Fonarow GC. Clinical presentation, management, and in-hospital outcomes of patients admitted with acute decompensated heart failure with preserved systolic function: a report from the Acute Decompensated Heart Failure National Registry (ADHERE) Database. J Am Coll Cardiol 2006;47:76-84.

8. Fonarow GC, Stough WG, Abraham WT, Albert NM, Gheorghiade $\mathrm{M}$, Greenberg $\mathrm{BH}$, et al. Characteristics, treatments, and outcomes of patients with preserved systolic function hospitalized for heart failure: a report from the OPTIMIZE-HF Registry. J Am Coll Cardiol 2007;50:768-77.

9. Lam CSP, Gamble GD, Ling LH, Sim D, Leong KTG, Yeo PSD, et al. Mortality associated with heart failure with preserved vs. reduced ejection fraction in a prospective international multiethnic cohort study. Eur Heart J 2018;39:1770-80.

10. Kebe B, Getachew M, Molla Y, Bahiru B, Dessie B. Management, survival, and predictors of mortality among hospitalized heart failure patients at Debre Markos comprehensive specialized hospital, Northwest Ethiopia: Prospective cohort study. SAGE Open Med 2021;9:20503121211057336.

11. Kristensen SL, Martinez F, Jhund PS, Arango JL, Bělohlávek J, Boytsov S, et al. Geographic variations in the PARADIGMHF heart failure trial. Eur Heart J 2016;37:3167-74.

12. Dokainish H, Teo K, Zhu J, Roy A, AlHabib KF, ElSayed A, et al. Global mortality variations in patients with heart failure: results from the International Congestive Heart Failure (INTERCHF) prospective cohort study. Lancet Glob Health 2017;5:e66572.

13. Crespo-Leiro MG, Anker SD, Maggioni AP, Coats AJ, Filippatos G, Ruschitzka F, et al. European Society of Cardiology Heart Failure Long-Term Registry (ESC-HF-LT): 1-year followup outcomes and differences across regions. Eur J Heart Fail 2016;18: 613-25.

14. Yılmaz MB, Çelik A, Çavuşoğlu Y, Bekar L, Onrat E, Eren $\mathrm{M}$, et al. Snapshot evaluation of heart failure in Turkey: Baseline characteristics of SELFIE-TR. Turk Kardiyol Dern Ars 2019;47:198-206.

15. Yılmaz MB, Aksakal E, Aksu U, Altay H, Nesligül Y, Çelik A, et al. Snapshot evaluation of acute and chronic heart failure in real-life in Turkey: a follow-up data for mortality. Anatol J Cardiol 2020;23:160-8.

16. Ponikowski P, Voors AA, Anker SD, Bueno H, Cleland JGF, Coats AJS, et al. 2016 ESC Guidelines for the diagnosis and treatment of acute and chronic heart failure: The Task Force for the diagnosis and treatment of acute and chronic heart failure of the European Society of Cardiology (ESC)Developed with the spe- 
cial contribution of the Heart Failure Association (HFA) of the ESC. Eur Heart J 2016;37: 2129-200.

17. McDonagh TA, Metra M, Adamo M, Gardner RS, Baumbach A, Böhm M, et al. 2021 ESC Guidelines for the diagnosis and treatment of acute and chronic heart failure. Eur Heart J 2021;42:3599-726.

18. Chioncel O, Lainscak M, Seferovic PM, Anker SD, CrespoLeiro MG, Harjola VP, et al. Epidemiology and one-year outcomes in patients with chronic heart failure and preserved, mid-range and reduced ejection fraction: an analysis of the ESC Heart Failure Long-Term Registry. Eur J Heart Fail 2017; 19:1574-85.

19. Ibanez B, James S, Agewall S, Antunes MJ, Bucciarelli-Ducci C, Bueno H, et al. 2017 ESC Guidelines for the management of acute myocardial infarction in patients presenting with ST-segment elevation: The Task Force for the management of acute myocardial infarction in patients presenting with ST-segment elevation of the European Society of Cardiology (ESC). Eur Heart J 2018;39:119-77.

20. Borlaug BA. Evaluation and management of heart failure with preserved ejection fraction. Nat Rev Cardiol 2020;17: 55973.

21. Degertekin M, Erol Ç, Ergene O, Tokgözoğlu L, Aksoy M, Erol MK, et al. Heart failure prevalence and predictors in Turkey: HAPPY study. Turk Kardiyol Dern Ars 2012;40:298-308.

22. Koh AS, Tay WT, Teng THK, Vedin O, Benson L, Dahlstrom $\mathrm{U}$, et al. A comprehensive population-based characterization of heart failure with mid-range ejection fraction. Eur J Heart Fail 2017;19:1624-34.

23. Vedin O, Lam CSP, Koh AS, Benson L, Teng THK, Tay WT, et al. Significance of ischemic heart disease in patients with heart failure and preserved, midrange, and reduced ejection fraction: a Nationwide Cohort Study. Circ Heart Fail 2017;10:e003875.

24. Kapoor JR, Kapoor R, Ju C, Heidenreich PA, Eapen ZJ, Hernandez AF, et al. Precipitating clinical factors, heart failure characterization, and outcomes in patients hospitalized with heart failure with reduced, borderline, and preserved ejection fraction. JACC Heart Fail 2016;4:464-72.

25. Özlek B, Özlek E, Ağuş HZ, Tekinalp M, Kahraman S, Çil $\mathrm{C}$, et al. Patients with HFpEF and HFmrEF have different clinical characteristics in Turkey: a multicenter observational study. Eur J Intern Med 2019;61:88-95.

26. Obokata M, Reddy YNV, Pislaru SV, Melenovsky V, Borlaug BA. Evidence supporting the existence of a distinct obese phenotype of heart failure with preserved ejection fraction. Circulation 2017;136:6-19.

27. Rao VN, Fudim M, Mentz RJ, Michos ED, Felker GM. Regional adiposity and heart failure with preserved ejection fraction. Eur J Heart Fail 2020;22:1540-50.

28. Packer M. Do most patients with obesity or type 2 diabetes, and atrial fibrillation, also have undiagnosed heart failure? A critical conceptual framework for understanding mechanisms and improving diagnosis and treatment. Eur J Heart Fail 2020;22:214-27.

29. Hicklin HE, Gilbert ON, Ye F, Brooks JE, Upadhya B. Hypertension as a road to treatment of heart failure with preserved ejection fraction. Curr Hypertens Rep 2020;22:82.

30. Mentz RJ, Kelly JP, von Lueder TG, Voors AA, Lam CS, Cowie MR, et al. Noncardiac comorbidities in heart failure with reduced versus preserved ejection fraction. J Am Coll Cardiol 2014;64:2281-93.

31. Koçyiğit D, Sarıül NU, Altın AT, Çay S, Polat V, Saygı S, et al. Current clinical practice of cardiac resynchronization therapy in Turkey: reflections from Cardiac Resynchronization Therapy Survey-II. Anatol J Cardiol 2020;24:382-96.

32. Aras D, Aydoğdu S, Bozkurt E, Çavuşoğlu Y, Eren M, Erol Ç, et al. Cost of heart failure management in Turkey: results of a Delphi Panel. Anatol J Cardiol 2016;16:554-62.

33. Gayat E, Arrigo M, Littnerova S, Sato N, Parenica J, Ishihara $\mathrm{S}$, et al. Heart failure oral therapies at discharge are associated with better outcome in acute heart failure: a propensity-score matched study. Eur J Heart Fail 2018;20:345-54.

34. McMurray JJ, Packer M, Desai AS, Gong J, Lefkowitz MP, Rizkala AR, et al. Angiotensin-neprilysin inhibition versus enalapril in heart failure. N Engl J Med 2014;371:993-1004.

35. Kocabaş U, Kıvrak T, Yılmaz Öztekin GM, Tanık VO, Özdemir IH, Kaya E, et al. Adherence to guideline-directed medical and device Therapy in outpAtients with heart failure with reduced ejection fraction: the ATA study. Anatol J Cardiol 2020;24:32-40.

36. McMurray JJV, Solomon SD, Inzucchi SE, Køber L, Kosiborod MN, Martinez FA, et al. Dapagliflozin in patients with heart failure and reduced ejection fraction. $\mathrm{N}$ Engl J Med 2019;381:1995-2008.

37. Packer M, Anker SD, Butler J, Filippatos G, Pocock SJ, Carson $\mathrm{P}$, et al. Cardiovascular and renal outcomes with empagliflozin in heart failure. N Engl J Med 2020;383:1413-24.

38. Anker SD, Butler J, Filippatos G, Ferreira JP, Bocchi E, Böhm $\mathrm{M}$, et al. Empagliflozin in heart failure with a preserved ejection fraction. N Engl J Med 2021;385:1451-61.

39. Solomon SD, McMurray JJV, Anand IS, Ge J, Lam CSP, Maggioni AP, et al. Angiotensin-neprilysin inhibition in heart failure with preserved ejection fraction. $N$ Engl $\mathrm{J}$ Med 2019;381:1609-20.

40. Pitt B, Zannad F, Remme WJ, Cody R, Castaigne A, Perez A, et al. The effect of spironolactone on morbidity and mortality in patients with severe heart failure. Randomized Aldactone Evaluation Study Investigators. N Engl J Med 1999;341:709-17.

41. Zannad F, McMurray JJ, Krum H, van Veldhuisen DJ, Swedberg K, Shi H, et al. Eplerenone in patients with systolic heart failure and mild symptoms. N Engl J Med 2011;364:11-21.

42. Çavuşoğlu Y, Zoghi M, Eren M, Bozçalı E, Kozdağ G, Şentürk T, et al. Post-discharge heart failure monitoring program in Turkey: Hit-PoinT. Anatol J Cardiol 2017;17:107-12. 